\title{
WEIGHT PRODUCT DALAM IMPLEMENTASI SISTEM PENDUKUNG KEPUTUSAN BANTUAN BEDAH RUMAH
}

\author{
Dwi Marisa Efendi ${ }^{1}$, Novita $^{2}$ \\ Teknik Komputer ${ }^{1}$, Sistem Informasi ${ }^{2}$ \\ ${ }^{1,2}$ STMIK Dian Cipta Cendikia Kotabumi \\ Jalan Negara No.03 Candimas, Lampung Utara \\ E-mail : dwi.marisa@dcc.ac.id ${ }^{1}$, novi1995ta@gmail.com,
}

\begin{abstract}
ABSTRAK
Lampung Utara adalah satu kabupaten yang ada di provinsi lampung.Pemerintanh mengualarkan program bantuan ,yang mana setiap derah diberi kesempatan untuk mengelola dana bantuan yang salah satunya adalah berupa bantuan bedah rumah.Program pemerintah yang baik ini haus di dukung dengan tingkat akurasi data, efeiensi waktu pengeloaan penerima banrtuan.Dalam hal penentuan penduduk yang berhak menerima bantuan ini harus bersifat onjektf.Oleh karena itu agar mendapatkan hasil yang baik, maka dalam penelitian ini menggunakan metode weight product dalam implementasi sistem pendukung keputusan penerima bedah rumah.
\end{abstract}

Kata kunci : dana,spk, weight product,akurasi.

\begin{abstract}
s
North Lampung is a district in Lampung province. The government issued an aid program, he program is that every region is given the opportunity to manage aid funds, one of which is in the form of home surgery, This good government program is thirsty supported by the level of data accuracy, efficiency of the time of the recipient's management. Therefore in order to get good results. Then in this study using the weight product method in the implementation of decision support systems for home surgery recipients. Keywords: funds, spk, weight product, accuracy
\end{abstract}

\section{PENDAHULUAN}

Program bedah rumah merupakan salah satu program bantuan stimulan permuhan swadaya (BSPS) yang diberikan kepad rakyat berpenghasilan rendah (MBR) yang kondisinya kurang layak.Untuk mendapatkan bantuan ini , pemerintah memebrikan bebera kriteria yang menjadi syarat untuk mendapatkan bantuan diantaranya[1].

I.Persyaratan umum

a) Kartu tanda penduduk(KTP)[2]

b) Kartu Keluarga (KK)[2]

II.Persyaratan khusus

a) Menguasai Tanah

b) Kondisi rumah

c) Jenis Pekerjaan

d) Penghasilan

e) Memiliki Keswadayaan

\section{I.1 Sistem}

Dalam penelitan sebelumnya menggunakan metode WP digunakan untuk menentukan pengankatan guru tetap, dengan beberapa kriteria yang ditentukan.[3]

Sistem adalah suatu kesatuan yang terdiri atas komponen atau elemen yang saling berinteraksi, saling terkait atau saling bergantung membentuk keseluruhan satuan yang kompleks[4]

\section{I.2 Pendukung Keputusan}

Keputusan merupakan hasil pemecahan masalah yang harus didasari logika dan pertimbangan,penetapan alternatif terbaik, harus mendekati tujuan yang telah ditetapkan dan memperhatikan hal-hal seperti logika,realitas, rasional, dan pragmatis[5] 
Ada banyak metode yang digunakan dalam menentukan kepusan yang cukup kompleks berdasrakan beberapa kriteria, salah satunya adalah [6] Dalam penelitian $\mathrm{Xu}$ dan $\mathrm{Li}$ dalam penelitiannya melakukan representai berbasis permutasi untuk memecahkan masalahnya berdasarkan tataletak situs kontruksi denganmenggunakan metode multi - objektive particle swam optimization algorithm (MOPSO) [7], Zavadskas dalam penelitian menngunakan jumlah tertimbang dan model produk tertimbang (WSM dan WPM) yang sudah dikenal secara luas dapat menyelesaikan pengambilan keputusan dengan di kombinasikan dengan metode TOPSIS sehingga bisa mendapatkan tingkat akurasi yang pasti dan mendekati nilai benar[8]

\section{METODE PENELITIAN}

\subsection{Tehnik Pengumpulan Data}

Dalam peenelitian ini metode pengumpulan data yang digunakan adalah

a) Metode Observasi

b) Metode Wawancara

c) Study Pustaka

d) Dokumentasi

\subsection{Metode weight product}

Penghutungan yang digunakan dalam sistem pendukung keputusan ini adalah menggunakan metode weight product, dan yang menjadi objek dari penelitian ini adalah warga-warga di Lampung Utara. Nilai dan bobot dari masingmasing kriteria yang dijadikan penentuan kelayakan penerima program BSPS.

\section{HASIL DAN PEMBAHASAN}

Berikut adalah analisa tehnik penghitungan dengan menggunkan menggunakan metode weight product :

\section{Menentukan alternatif}

Dalam penelitian ini yang menjadi alternatif adalah warga-warga Kecamatan Kotabumi Selatan dengan sempel sebanyak 40 orang.

2 Menentukan Kriteria

Kriterian yang digunakan dalam penentuan penerima program bantuan stimulan perumahan swadaya adalah sebagai berikut :

\section{Tabel 4 Kriteria Penerima Program Bantuan Stimulan Perumahan Swadaya}

\begin{tabular}{|c|c|}
\hline Kriteria & Keterangan \\
\hline $\mathrm{C} 1$ & Menguasai Tanah \\
\hline $\mathrm{C} 2$ & Kondisi Rumah \\
\hline $\mathrm{C} 3$ & Jenis Pekerjaan \\
\hline $\mathrm{C} 4$ & Penghasilan \\
\hline $\mathrm{C} 5$ & Keswadayaan \\
\hline
\end{tabular}

3.Menentukan Bobot awal

Tabel 5. Bobot Untuk Menguasai Tanah

\begin{tabular}{|c|c|}
\hline Menguasai Tanah & Bobot \\
\hline Serifikat Tanah & 4 \\
\hline Akta Jual Beli Tanah & 3 \\
\hline
\end{tabular}

Tabel 6. Bobot Untuk Kondisi Rumah

\begin{tabular}{|c|c|}
\hline Kondisi Rumah & Bobot \\
\hline Geribik & 4 \\
\hline Papan & 3 \\
\hline Panggung & 2 \\
\hline Bata atau Permanen & 1 \\
\hline
\end{tabular}

Tabel 7. Bobot Untuk Jenis Pekerjaan

\begin{tabular}{|c|c|}
\hline Jenis Pekerjaan & Bobot \\
\hline Buruh & 4 \\
\hline Wira swata & 3 \\
\hline PNS & 2 \\
\hline
\end{tabular}

Tabel 8. Bobot Untuk Penghasilan

\begin{tabular}{|c|c|}
\hline Penghasilan & Bobot \\
\hline$<$ Rp.750.000 & 4 \\
\hline Rp.750.000 s/d Rp. 1.000 .000 & 3 \\
\hline Rp. 1.000 .000 s/d Rp 1.200 .000 & 2 \\
\hline
\end{tabular}

Tabel 9. Keswadayaan

\begin{tabular}{l|l} 
Keswadayaan & Bobot
\end{tabular}




\begin{tabular}{|l|c|}
\hline $\begin{array}{l}\text { Memiliki Tabungan } \\
\text { Bahan Bangunan }\end{array}$ & 4 \\
\hline $\begin{array}{l}\text { Memiliki Aset lain yang } \\
\text { akan dijadikan dana } \\
\text { tambahan BSPS }\end{array}$ & 3 \\
\hline $\begin{array}{l}\text { Memiliki Tabungan } \\
\text { Bahan Bangunan }\end{array}$ & 2 \\
\hline
\end{tabular}

Pada setiap alternatif kriteria dinilai 4 sampai 1 yaitu

\section{Tabel 10. Pembobotan Kriteria}

\begin{tabular}{|c|c|c|}
\hline Kriteria & Skala & Bobot \\
\hline \multirow[b]{2}{*}{$\begin{array}{l}\text { Mengasa } \\
\text { i Tanah }\end{array}$} & Sertifikat Tanah & 4 \\
\hline & $\begin{array}{l}\text { Akta Jual Beli } \\
\text { Tanah }\end{array}$ & 3 \\
\hline \multirow{4}{*}{$\begin{array}{l}\text { Kondisi } \\
\text { Rumah }\end{array}$} & Geribik & 4 \\
\hline & Papan & 3 \\
\hline & Panggung & 2 \\
\hline & $\begin{array}{ll}\text { Bata } & \text { atau } \\
\text { Permanen } & \end{array}$ & 1 \\
\hline \multirow{3}{*}{$\begin{array}{l}\text { Jenis } \\
\text { Pekerjaa } \\
\mathrm{n}\end{array}$} & Buruh & 4 \\
\hline & Wirasuwasta & 3 \\
\hline & PNS & 2 \\
\hline \multirow{4}{*}{$\begin{array}{l}\text { Penghasi } \\
\text { lan }\end{array}$} & $<$ Rp.750.000 & 4 \\
\hline & $\begin{array}{l}\text { Rp.750.000 s/d } \\
\text { Rp.1.000.000 }\end{array}$ & 3 \\
\hline & $\begin{array}{lr}\text { Rp. } & 1.000 .000 \\
\text { s/d } & \text { Rp } \\
1.200 .000 & \\
\end{array}$ & 2 \\
\hline & $>\operatorname{Rp} 1.200 .000$ & 1 \\
\hline \multirow{2}{*}{$\begin{array}{l}\text { Keswada } \\
\text { yaan }\end{array}$} & $\begin{array}{l}\text { Memiliki } \\
\text { Tabungan } \\
\text { Bahan } \\
\text { Bangunan }\end{array}$ & 4 \\
\hline & $\begin{array}{l}\text { Memiliki Aset } \\
\text { lain yang akan } \\
\text { dijadikan dana } \\
\text { tambahan BSPS }\end{array}$ & 3 \\
\hline
\end{tabular}

4. Memasukan Bobot yang ditentukan oleh User

Tabel 13. Bobot Masukan User

\begin{tabular}{|c|c|}
\hline Kriteria & Bobot \\
\hline Menguasai Tanah & 4 \\
\hline Kondisi Rumah & 4 \\
\hline Jenis Pekerjaan & 3 \\
\hline Penghasilan & 3 \\
\hline Keswadayaan & 2 \\
\hline
\end{tabular}

Selanjutnya akan Dilakuakan perbaikan bobot terlabih dahulu. Bobot awal $\mathrm{W}=(4,4,3,3,2$, ) akan diperbaiki sehingga total bobot $\sum \mathrm{Wj}=1$ dengan $\mathrm{w}$ adalah bobot dari masing-masing kriteria yang user masukan. Adapun perhitungan perbaikan kriterianya adalah :

$\mathrm{W} 1=4 /(4+4+3+3+2)=4 / 16=0,25$

$\mathrm{W} 2=4 /(4+4+3+3+2)=4 / 16=0,25$

$\mathrm{W} 3=3 /(4+4+3+3+2)=3 / 16=0,1875$

$\mathrm{W} 4=3 /(4+4+3+3+2)=3 / 16=0,1875$

$\mathrm{W} 5=2 /(4+4+3+3+2)=2 / 16=0,125$

Berikitnya perbaikan bobot dari masukan user

Tabel 14. Perbaikan Bobot dari MasukanUser

\begin{tabular}{|c|c|c|}
\hline Kriteria & Bobot & $\begin{array}{c}\text { Perbaikan } \\
\text { Bobot }\end{array}$ \\
\hline Menguasai Tanah & 4 & 0,25 \\
\hline Kondisi Rumah & 4 & 0,25 \\
\hline Jenis Pekerjaan & 3 & 0,1875 \\
\hline Penghasilan & 3 & 0,1875 \\
\hline Keswadayaan & 2 & 0,124 \\
\hline
\end{tabular}

Kemudian langkah selanjutnya menghitung vektor $\mathrm{S}, \mathrm{S}$ adalah nilai dari setiap alternatif. Penghitungan ini dialakukan dengan mengalikan seluruh atribut (kriteria) bagi sebuah alternatif $W$ (bobot) sebagai perangakat positif untuk atribut keuntungan dan bobot berpangkat negatif untuk atribut biaya

Setelah mendapat niali dari vektor S, selanjutnya menentukatn perangkingan alternatif warga di kecamatan Kotabumi Selatan dengan cara membagi nilai $\mathrm{V}$ atau (nilai vektor yang digunakan untuk perangkingan) bagi setiap alternatif dengan niali total dari semua niali alternatif (vector $S$ ) berikut ini perhitungannya :

Setelah menghitung nilai vector $\mathrm{V}$ maka didapat rekomendasi hasil perengkingan

\begin{tabular}{|l|l|l|l|l|}
\hline $\mathrm{N}$ & Vekt & Nilai & Alternatif & Rangki \\
\hline
\end{tabular}




\begin{tabular}{|c|c|c|c|c|}
\hline 0 & or & & & ng \\
\hline \multirow[t]{2}{*}{1} & & 0,012 & & \\
\hline & V1 & 0 & Ismanto & 1 \\
\hline \multirow[t]{2}{*}{2} & & 0,011 & Budi Yoni & \\
\hline & V2 & 6 & & 2 \\
\hline \multirow{2}{*}{3} & & 0,011 & Bisri & \\
\hline & V3 & 6 & & 2 \\
\hline \multirow[t]{2}{*}{4} & & 0,011 & & \\
\hline & V4 & 5 & Yunus & 3 \\
\hline \multirow[t]{2}{*}{5} & & 0,011 & Budi & \\
\hline & V5 & 2 & Saputra & 4 \\
\hline \multirow[t]{2}{*}{6} & & 0,011 & Yoni & \\
\hline & V6 & 2 & Sulistio & 4 \\
\hline \multirow[t]{3}{*}{7} & & & Tego & \\
\hline & & 0,011 & Wijayant & \\
\hline & V7 & 2 & 0 & 4 \\
\hline \multirow[t]{2}{*}{8} & & 0,011 & Panut & \\
\hline & V8 & 1 & & 5 \\
\hline \multirow[t]{2}{*}{9} & & 0,011 & Selamet & \\
\hline & V9 & 1 & & 5 \\
\hline \multirow[t]{2}{*}{10} & & 0,011 & & \\
\hline & V10 & 0 & Rafi & 6 \\
\hline \multirow[t]{2}{*}{11} & & 0,011 & & \\
\hline & V11 & 0 & Jono & 6 \\
\hline \multirow[t]{2}{*}{12} & & 0,010 & & \\
\hline & V12 & 9 & Yunizar & 7 \\
\hline \multirow[t]{2}{*}{13} & & 0,010 & Basri & \\
\hline & V13 & 9 & & 7 \\
\hline \multirow[t]{2}{*}{14} & & 0,010 & & \\
\hline & V14 & 9 & Musbar & 7 \\
\hline \multirow[t]{2}{*}{15} & & 0,010 & & \\
\hline & V15 & 9 & Yongki & 7 \\
\hline \multirow[t]{3}{*}{16} & & & Eko & \\
\hline & & 0,010 & Heriyant & \\
\hline & V16 & 7 & 0 & 8 \\
\hline \multirow[t]{3}{*}{17} & & & Eko & \\
\hline & & 0,010 & Heriyant & \\
\hline & V17 & 7 & 0 & 8 \\
\hline \multirow[t]{2}{*}{18} & & 0,010 & & \\
\hline & V18 & 7 & Darto & 8 \\
\hline \multirow[t]{2}{*}{19} & & 0,010 & Zaili & \\
\hline & V19 & 7 & Efendi & 8 \\
\hline \multirow[t]{2}{*}{20} & & 0,010 & Darudin & \\
\hline & V20 & 7 & & 8 \\
\hline \multirow[t]{2}{*}{21} & & 0,010 & & \\
\hline & V21 & 7 & Teja & 8 \\
\hline
\end{tabular}

\begin{tabular}{|c|c|c|c|c|}
\hline 22 & רבע & 0,010 & Pruidi & 8 \\
\hline 23 & V23 & 0,010 & Rarualin & 8 \\
\hline 24 & V24 & $\begin{array}{c}0,010 \\
7\end{array}$ & Sirat & 8 \\
\hline 25 & V25 & $\begin{array}{c}0,010 \\
5\end{array}$ & Amrizal & 9 \\
\hline 26 & V26 & $\begin{array}{c}0,010 \\
4\end{array}$ & $\begin{array}{l}\text { Abdul } \\
\text { Rohman }\end{array}$ & 10 \\
\hline 27 & V27 & $\begin{array}{c}0,010 \\
4\end{array}$ & Ridwan & 10 \\
\hline 28 & V28 & $\begin{array}{c}0,010 \\
4\end{array}$ & Amdani & 10 \\
\hline 29 & V29 & $\begin{array}{c}0,010 \\
4\end{array}$ & Ashari & 10 \\
\hline 30 & V30 & $\begin{array}{c}0,010 \\
4 \\
\end{array}$ & $\begin{array}{l}\text { Rendi } \\
\text { Supriyant } \\
\text { o }\end{array}$ & 10 \\
\hline 31 & V31 & $\begin{array}{c}0,010 \\
4\end{array}$ & Yadi & 10 \\
\hline 32 & V32 & $\begin{array}{c}0,010 \\
4\end{array}$ & $\begin{array}{l}\text { Irwan } \\
\text { Mardian }\end{array}$ & 10 \\
\hline 33 & V33 & $\begin{array}{c}0,010 \\
3\end{array}$ & Romli & 12 \\
\hline 34 & V34 & $\begin{array}{c}0,010 \\
3\end{array}$ & $\begin{array}{l}\text { Darman } \\
\text { Hernanto }\end{array}$ & 12 \\
\hline 35 & V35 & $\begin{array}{c}0,010 \\
3\end{array}$ & Handoko & 12 \\
\hline 36 & V36 & $\begin{array}{c}0,010 \\
3\end{array}$ & Julianto & 13 \\
\hline 37 & V37 & $\begin{array}{c}0,010 \\
3\end{array}$ & $\begin{array}{l}\text { Bejo } \\
\text { Sukarji }\end{array}$ & 13 \\
\hline 38 & V38 & $\begin{array}{c}0,010 \\
2 \\
\end{array}$ & Tumino & 14 \\
\hline 39 & V39 & $\begin{array}{c}0,010 \\
0\end{array}$ & Gustam & 15 \\
\hline 40 & V40 & $\begin{array}{c}0,010 \\
0\end{array}$ & Asepudin & 15 \\
\hline 41 & V41 & $\begin{array}{c}0,010 \\
0\end{array}$ & $\begin{array}{l}\text { Ismail } \\
\text { Ropif }\end{array}$ & 15 \\
\hline 42 & V42 & $\begin{array}{c}0,010 \\
0 \\
\end{array}$ & $\begin{array}{l}\text { Martalen } \\
\text { si }\end{array}$ & 15 \\
\hline 43 & V43 & $\begin{array}{c}0,010 \\
0 \\
\end{array}$ & Mujiono & 15 \\
\hline 44 & V44 & $\begin{array}{c}0,010 \\
0\end{array}$ & $\begin{array}{l}\text { Saipul } \\
\text { Jen }\end{array}$ & 15 \\
\hline
\end{tabular}




\begin{tabular}{|c|c|c|c|c|}
\hline 45 & V45 & $\begin{array}{c}0,010 \\
0\end{array}$ & $\begin{array}{l}\text { Dani } \\
\text { Safrijal }\end{array}$ & 15 \\
\hline 46 & V46 & $\begin{array}{c}0,010 \\
0\end{array}$ & Firman & 15 \\
\hline 47 & V47 & $\begin{array}{c}0,010 \\
0\end{array}$ & $\begin{array}{l}\text { Yayan } \\
\text { Asnawi }\end{array}$ & 15 \\
\hline 48 & V48 & $\begin{array}{c}0,010 \\
0\end{array}$ & $\begin{array}{l}\text { Badarudi } \\
\mathrm{n}\end{array}$ & 15 \\
\hline 49 & V49 & $\begin{array}{c}0,010 \\
0\end{array}$ & Feri & 15 \\
\hline 50 & V50 & $\begin{array}{c}0,010 \\
0\end{array}$ & Muhtar & 15 \\
\hline 51 & V51 & $\begin{array}{c}0,010 \\
0\end{array}$ & $\begin{array}{l}\text { Fajar } \\
\text { Hidayat }\end{array}$ & 15 \\
\hline 52 & V52 & $\begin{array}{c}0,010 \\
0\end{array}$ & Juntet & 15 \\
\hline 53 & V53 & $\begin{array}{c}0,010 \\
0\end{array}$ & $\begin{array}{l}\text { Ramaulla } \\
\mathrm{h}\end{array}$ & 15 \\
\hline 54 & V54 & $\begin{array}{c}0,010 \\
0\end{array}$ & Gimo & 15 \\
\hline 55 & V55 & $\begin{array}{c}0,010 \\
0 \\
\end{array}$ & $\begin{array}{l}\text { Dedi } \\
\text { Mulyadi }\end{array}$ & 15 \\
\hline 56 & V56 & $\begin{array}{c}0,010 \\
0\end{array}$ & $\begin{array}{l}\text { Jainudin } \\
\text { Sefriansy } \\
\text { ah }\end{array}$ & 15 \\
\hline 57 & V57 & $\begin{array}{c}0,010 \\
0\end{array}$ & $\begin{array}{l}\text { Adi } \\
\text { Kurniawa } \\
\mathrm{n}\end{array}$ & 15 \\
\hline 58 & V58 & $\begin{array}{c}0,010 \\
0\end{array}$ & $\begin{array}{l}\text { Asnan } \\
\text { Prabowo }\end{array}$ & 15 \\
\hline 59 & V59 & $\begin{array}{c}0,010 \\
0 \\
\end{array}$ & $\begin{array}{l}\text { Khoirul } \\
\text { Amin }\end{array}$ & 15 \\
\hline 60 & V60 & $\begin{array}{c}0,010 \\
0 \\
\end{array}$ & Ansori & 15 \\
\hline 61 & V61 & $\begin{array}{c}0,010 \\
0\end{array}$ & Paryono & 15 \\
\hline 62 & V62 & $\begin{array}{c}0,010 \\
0\end{array}$ & $\begin{array}{l}\text { Ismail } \\
\text { Alam }\end{array}$ & 15 \\
\hline 63 & V63 & $\begin{array}{c}0,010 \\
0 \\
\end{array}$ & $\begin{array}{l}\text { Eka } \\
\text { Budiyono }\end{array}$ & 15 \\
\hline 64 & V64 & $\begin{array}{c}0,010 \\
0\end{array}$ & $\begin{array}{l}\text { Amar } \\
\text { Safei }\end{array}$ & 15 \\
\hline 65 & V65 & $\begin{array}{c}0,010 \\
0\end{array}$ & $\begin{array}{l}\text { Sandi } \\
\text { Sute }\end{array}$ & 15 \\
\hline 66 & V66 & $\begin{array}{c}0,009 \\
8\end{array}$ & Dadang & 16 \\
\hline
\end{tabular}

\begin{tabular}{|c|c|c|c|c|}
\hline 67 & V67 & $\begin{array}{c}0,009 \\
8 \\
\end{array}$ & Alanudin & 16 \\
\hline 68 & V68 & $\begin{array}{c}0,009 \\
7\end{array}$ & Mursalim & 17 \\
\hline 69 & V69 & $\begin{array}{c}0,009 \\
7\end{array}$ & Dadang & 17 \\
\hline 70 & V70 & $\begin{array}{c}0,009 \\
5\end{array}$ & Reno & 18 \\
\hline 71 & V71 & $\begin{array}{c}0,009 \\
4\end{array}$ & $\begin{array}{l}\text { Rahmat } \\
\text { Hidayat }\end{array}$ & 19 \\
\hline 72 & V72 & $\begin{array}{c}0,009 \\
4\end{array}$ & $\begin{array}{l}\text { Amril } \\
\text { Muhidin }\end{array}$ & 19 \\
\hline 73 & V73 & $\begin{array}{c}0,009 \\
4\end{array}$ & Dadang & 19 \\
\hline 74 & V74 & $\begin{array}{c}0,009 \\
4\end{array}$ & Doni & 19 \\
\hline 75 & V75 & $\begin{array}{c}0,009 \\
4\end{array}$ & $\begin{array}{l}\text { Romi } \\
\text { Ardianto }\end{array}$ & 19 \\
\hline 76 & V76 & $\begin{array}{c}0,009 \\
4\end{array}$ & Sumarno & 19 \\
\hline 77 & V77 & $\begin{array}{c}0,009 \\
4\end{array}$ & $\begin{array}{l}\text { Adi } \\
\text { Suhardi }\end{array}$ & 19 \\
\hline 78 & V78 & $\begin{array}{c}0,009 \\
4\end{array}$ & Ardianto & 19 \\
\hline 79 & V79 & $\begin{array}{c}0,009 \\
4\end{array}$ & Jainadi & 19 \\
\hline 80 & V80 & $\begin{array}{c}0,009 \\
4\end{array}$ & Wandil & 19 \\
\hline 81 & V81 & $\begin{array}{c}0,009 \\
4\end{array}$ & Rudi & 19 \\
\hline 82 & V82 & $\begin{array}{c}0,009 \\
4\end{array}$ & Witan & 19 \\
\hline 83 & V83 & $\begin{array}{c}0,009 \\
0 \\
\end{array}$ & $\begin{array}{l}\text { Imam } \\
\text { Romadh } \\
\text { on }\end{array}$ & 20 \\
\hline 84 & V84 & $\begin{array}{c}0,009 \\
0\end{array}$ & $\begin{array}{l}\text { Aceng } \\
\text { Hanafi }\end{array}$ & 20 \\
\hline 85 & V85 & $\begin{array}{c}0,009 \\
0\end{array}$ & $\begin{array}{l}\text { Ahmad } \\
\text { Jaki }\end{array}$ & 20 \\
\hline 86 & V86 & $\begin{array}{c}0,009 \\
0\end{array}$ & $\begin{array}{l}\text { Khoiril } \\
\text { Azinar }\end{array}$ & 20 \\
\hline 87 & V87 & $\begin{array}{c}0,009 \\
0\end{array}$ & $\begin{array}{l}\text { Rehando } \\
\text { yo }\end{array}$ & 20 \\
\hline 88 & V88 & $\begin{array}{c}0,009 \\
0\end{array}$ & Danang & 20 \\
\hline 89 & V89 & $\begin{array}{c}0,009 \\
0\end{array}$ & Riki & 20 \\
\hline
\end{tabular}




\begin{tabular}{|c|c|c|c|c|}
\hline 90 & V90 & $\begin{array}{c}0,009 \\
0\end{array}$ & Suyanto & 20 \\
\hline 91 & V91 & $\begin{array}{c}0,009 \\
0\end{array}$ & Hariudin & 20 \\
\hline 92 & V92 & $\begin{array}{c}0,009 \\
0\end{array}$ & $\begin{array}{l}\text { Rohmudi } \\
\mathrm{n}\end{array}$ & 20 \\
\hline 93 & V93 & $\begin{array}{c}0,008 \\
9\end{array}$ & $\begin{array}{l}\text { Bono } \\
\text { Tabroni }\end{array}$ & 21 \\
\hline 94 & V94 & $\begin{array}{c}0,008 \\
8\end{array}$ & Agus & 22 \\
\hline 95 & V95 & $\begin{array}{c}0,008 \\
8\end{array}$ & Mulyadi & 23 \\
\hline 96 & V96 & $\begin{array}{c}0,008 \\
8\end{array}$ & Iswandi & 23 \\
\hline 97 & V97 & $\begin{array}{c}0,008 \\
8\end{array}$ & $\begin{array}{l}\text { Rudi } \\
\text { Widodo }\end{array}$ & 23 \\
\hline 98 & V98 & $\begin{array}{c}0,008 \\
8\end{array}$ & Febriyadi & 23 \\
\hline 99 & V99 & $\begin{array}{c}0,008 \\
5\end{array}$ & Herli & 24 \\
\hline $\begin{array}{c}10 \\
0\end{array}$ & V100 & $\begin{array}{c}0,008 \\
5\end{array}$ & $\begin{array}{l}\text { Kamaludi } \\
\mathrm{n}\end{array}$ & 24 \\
\hline
\end{tabular}

Mencari Nilai MSE

Setelah melakukan perhitungan menggunakan excell selanjutnya adalah uji coba dengan menghitung nilai eror yaitu dengan membandingkan perhitungan manual dan perhitungan menggunakan microsoft excel. Penulis mencari nilai eror dari 100 alternatif atau sampel penulis mencari niali eror dari masingmasing 40 sampel dari manual dan 40 sampel dari excel dengan rumus :

Jumlah nilai manual - jumlah nilai/ Manual $\mathrm{x}$ $100 \%$

Hasil : Manual x 100\%

Penerapan dari masing-masing 40 sampel

$$
\text { Jumlah Manual Jumlah Excel }
$$$$
0,6049 \quad 0,4000
$$

$0,6049-0,4000: 0,6049 \times 100 \%=0,056396018$

$$
=0,056396018: 0,6049 \mathrm{x}
$$

$100 \%$

$$
\begin{aligned}
& =-0,093231969 \\
& =-9 \%
\end{aligned}
$$

Jadi nilai eror untuk penghitungan manual dan excel adalah $-9 \%$

\section{PENUTUP}

Hasil yang di capai oleh sistem menghasilkan 100 alternatif yang telah di urutkan dari alternatif terbesar sampai alternatif terkecil taitu menghasilkan 32 alternatif dengan rangking 1 sampai 10 yang dapat menjadi pertimbangan dalam menentukan tuan stimulan perumhan swdaya.

Beedasarkan uji coba validasi bahwa Microsoft Excel dapat digunankan karena nilai eror sedikit hanya $-9 \%$

\section{DAFTAR PUSTAKA}

[1] Monita, Dita. "Sistem pendukung keputusan penerima bantuan langsung tunai dengan menggunakan metode Analytical Hierarcy Process." Pelita Informatika: Informasi dan Informatika 3.2 (2013).

[2] Efendi, Dwi Marisa. "PENERAPAN ALGORITMA JARINGAN SYARAF TIRUAN UNTUK PREDIKSI KELAYAKAN KREDIT DI KOPERASI BINA BERSAMA LAMPUNG UTARA." Prosiding Seminar Nasional Darmajaya. Vol. 1. No. 1. 2017.

[3] Barus, Safrizal, et al. "Sistem Pendukung Keputusan Pengangkatan Guru Tetap Menerapkan Metode Weight Aggregated Sum Product Assesment (WASPAS)." MEDIA INFORMATIKA BUDIDARMA 2.2 (2018).

[4] Ardhy, Ferly. "SISTEM PENGAMBLAN KEPUTUSAN PEMILIHAN BIBIT JAGUNG DENGAN METODE ANALYTICAL HIERARCHY PROCESS (AHP) PADA TOKO ABADI JAYA LAMPUNG TIMUR." Jurnal Informasi dan Komputer 6.2 (2018): 73-80.

[5] Sinaga, Bosker. "Sistem Pendukung Keputusan Siswa Berprestasi Menggunakan Metode Analytic Hierarchy Process (AHP) Pada SMK Singosari Delitua." Jurnal Mantik Penusa16.2 (2014).

[6] Zavadskas, Edmundas Kazimieras, et al. "Multi-criteria assessment of facades' alternatives: peculiarities of ranking methodology." Procedia Engineering 57 (2013): 107-112. 
[7] Xu, Jiuping, and Zongmin Li. "Multiobjective dynamic construction site layout planning in fuzzy random environment." Automation in Construction 27 (2012): 155-169.

[8] Zavadskas, Edmundas Kazimieras, et al. "Extension of weighted aggregated sum product assessment with interval-valued intuitionistic fuzzy numbers (WASPAS-IVIF)." Applied soft computing 24 (2014): 10131021. 
